\title{
Necrotizing fasciitis: A decade of surgical intensive care experience
}

\section{Nissar Shaikh}

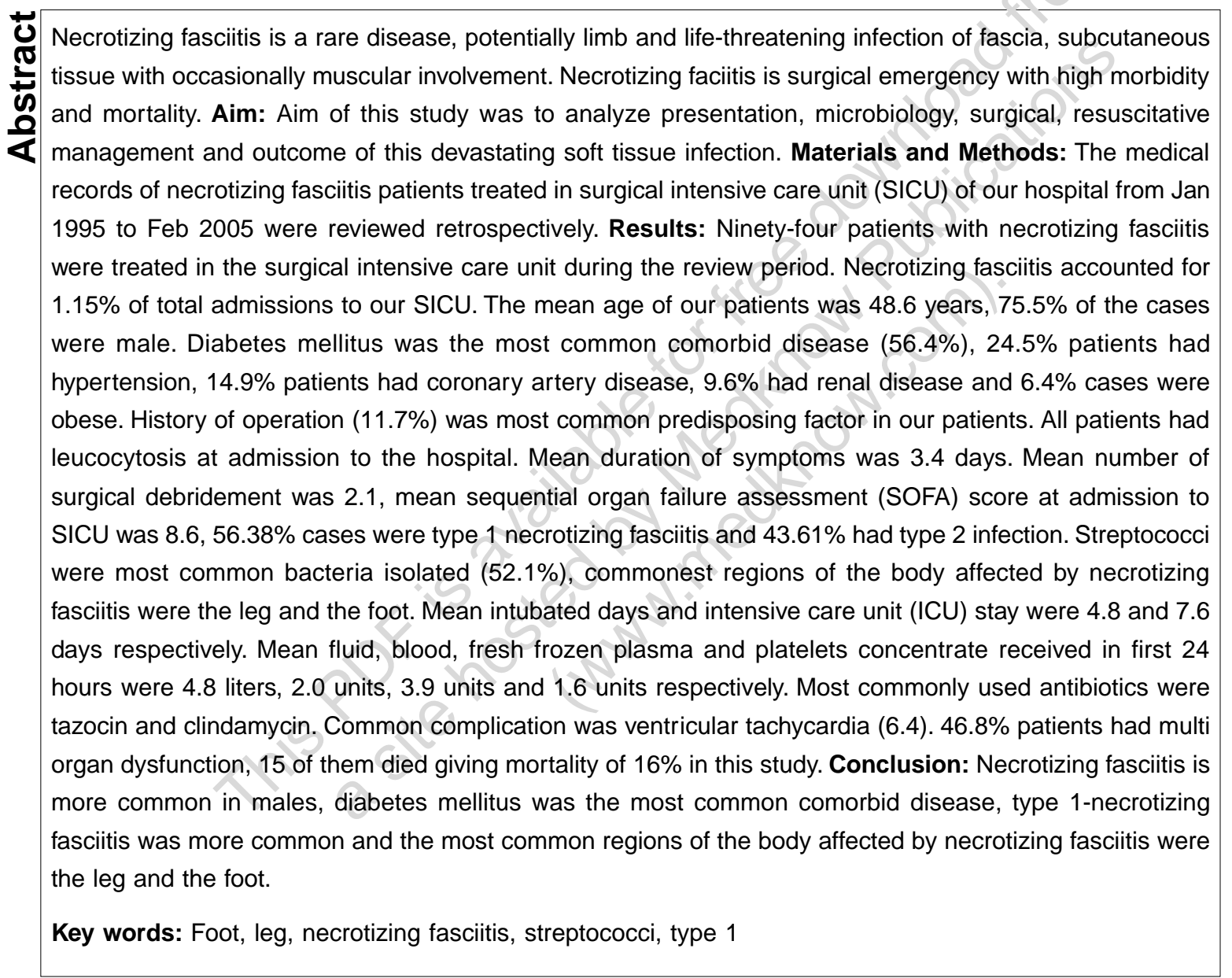

Necrotizing fasciitis is rapidly spreading and potentially devastating soft tissue infection. It is a progressive

From:

Department of Anesthesia, Hamad Medical Corporation, Doha-Qatar

Correspondence:

Dr. Nissar Shaikh, Department of Anesthesia/ICU and Pain Mgt, Hamad Medical Corporation, P.O. Box 3050, Doha-Qatar.

E-mail: nissarfirdous@hotail.com infectious process primarily involving fascia and subcutaneous tissue, with thrombosis of cutaneous microcirculation. Necrotizing fasciitis is a life and limb threatening surgical emergency that has been recognized for centuries dating back to Hippocrates in fifth century $B C .{ }^{[1]}$ Wilson first used the term necrotizing fasciitis in 1952 to describe the disease. ${ }^{[2]}$ A variety of 
terms have been used to describe the same condition including hospital gangrene, progressive bacterial synergistic gangrene, fuornier's gangrene, streptococcal gangrene and flesh eating bacterial infection. Necrotizing fasciitis is an uncommon disease and prognosis hinges on accurate early diagnosis and immediate institution of appropriate treatment.

The purpose of present study was to analyze presentation, type of infection, predisposing and comorbid conditions, surgical and resuscitative treatment and outcome of this soft tissue infection.

\section{Materials and Methods}

Our hospital is a 1444 bedded tertiary medical care centre with a 12-bed surgical intensive care unit (SICU). The medical records of necrotizing fasciitis patients treated in SICU between Jan 1995 and Feb 2005 were reviewed retrospectively. Only those patients with histopathology confirming the diagnosis were included in the study.

The variables that were examined in the present study includes age, gender, location of necrotizing fasciitis, duration of symptoms, presentation, predisposing factors, comorbid disease, severity of the disease, surgical and initial resuscitation, complications, intensive care unit (ICU) stay and outcome of this surgical emergency.

Statistical analyses were performed with use of SPSS statistical software. Bivariate analysis was performed with chi-square test or fisher's exact probability test for comparisons of proportion between groups- $P$ value $<$ 0.05 was considered significant.

\section{Results}

Ninety-four patients with necrotizing fasciitis were treated at our SICU during the period under review, which accounts for $1.15 \%$ of total admissions to surgical intensive care unit during the said period. Mean age of our patients was $48.6 \pm 16.3$ years [Table 1], $75.5 \%$ of patients were male. Non insulin dependent diabetes mellitus (NIDDM) was the most common comorbid condition (56.4\%), 24.5\% patients had hypertension (HTN), 14.9\% had coronary artery disease (CAD), 9.6\% had kidney disorders, $6.4 \%$ were obese, 5.3\% had chronic obstructive pulmonary diseases (COPD) and $2.1 \%$ of these patients had bronchial asthma (Asthma).
Table 1: Age, severity, fluid, blood, blood products needed and intensive care unit stay

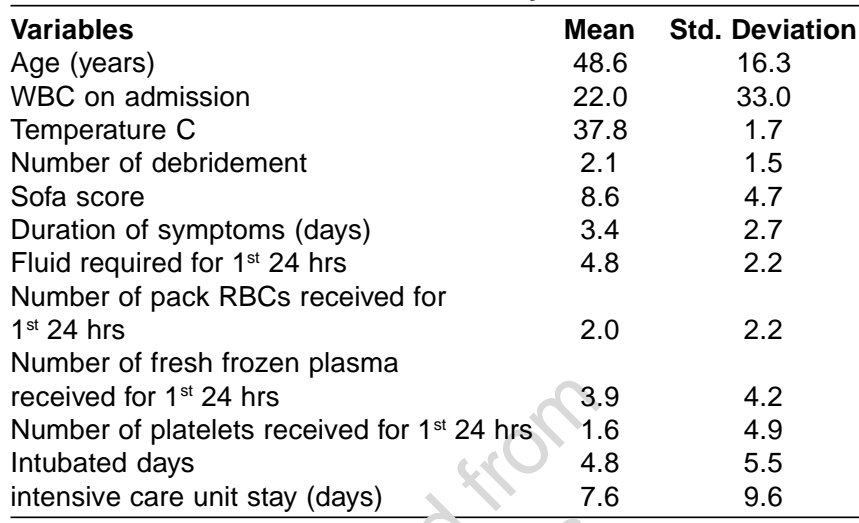

The common predisposing factor for necrotizing fasciitis in this study was operative procedure $(11.7 \%)$, four patients developed necrotizing fasciitis after incision and drainage of abscess, one each after hip surgery, dilatation and curettage, episiotomy, abdominal surgery, above knee amputation, dental extraction and emergency treacheostomy. History of trauma (10.6\%) and $2.1 \%$ patient had history of insect bite. $48.9 \%$ of our patients received nonsteroidal anti inflammatory drugs (NSAID) [Table 2]. All our patients had fever and leucocytosis on admission to the hospital.

Mean duration of symptoms was $3.4 \pm 2.7$ days, number of debridment our patients had was $2.1 \pm 1.5$ times, Sequential organ failure assessment (SOFA) score at admission to SICU was $8.6 \pm 4.7$, fluid, packed red

Table 2: Co-morbidities, predisposing factors and complications

\begin{tabular}{lcc}
\hline Variables & Frequency & Percentage \\
Sex & 71 & 75.5 \\
Male & 23 & 24.5 \\
Female & & \\
Co-morbid conditions & 53 & 56.4 \\
NIDDM & 14 & 14.9 \\
CAD & 23 & 24.5 \\
HTN & 9 & 9.6 \\
Kidney disease & 5 & 5.3 \\
COPD & 2 & 2.1 \\
Asthma & 6 & 6.4 \\
Obesity & & \\
Predisposing factors & 11 & 11.7 \\
History of operation & 10 & 10.6 \\
History of trauma & 2 & 2.1 \\
History of insect bite & 46 & 48.9 \\
History of NSAID & & \\
Complications & 5 & 5.3 \\
Compartment syndrome & 6 & 6.4 \\
Ventricular tachycardia & 1 & 1.1 \\
Tension pneumothorax & 2 & 2.1 \\
Acute renal failure &
\end{tabular}


blood cell (PRBC), fresh frozen plasma (FFP) and platelet concentrate received were $4.8 \pm 2.2$ liters, $2.0 \pm 2.2$ units, $3.9 \pm 4.9$ units and $1.6 \pm 4.9$ units respectively in first 24 hours of admission to SICU. The intubated days were 4.8 \pm 5.5 days and SICU stay was $7.6 \pm 9.6$ days [Table 1].

The common bacteria isolated from the necrotic tissue of these patients was streptococci (streptococci pyogenouseandstreptococci agalaectiace) (52.1\%) then Staphylococcus aureus (39.4\%) E. coli (Eschercia coli) $22.3 \%$, Pseudomonas aeroginosa $14.9 \%$, bacteriods $14.9 \%$, Klebsiella pneumonia $5.3 \%$ and Aeromonas sobori in $1.1 \%$ of the patients [Figure 1]. The most common region affected by necrotizing fasciitis was the leg and the foot (33\%) then the thigh (21.3\%), the prenium and the genitalia $20.2 \%$, the chest flank and axilla $8.5 \%$, gluteal and hip $8.5 \%$, arm, forearm and hand $7.5 \%$, cervical $5.3 \%$ and the abdomen involved in $2.1 \%$ of the patients [Figure 2]. Eighty two percent patients received two antibiotics while $17 \%$ received three antibiotic combination, most commonly

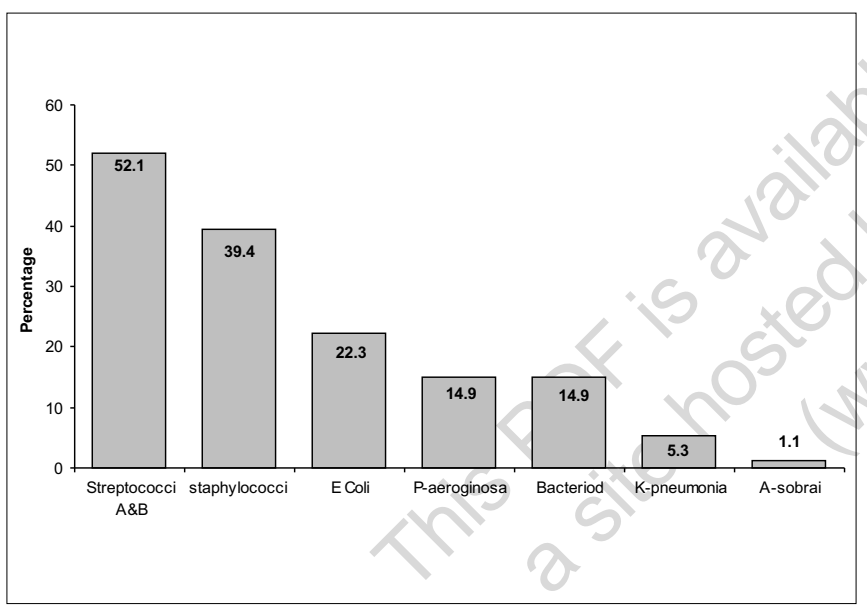

Figure 1: Bacteriology

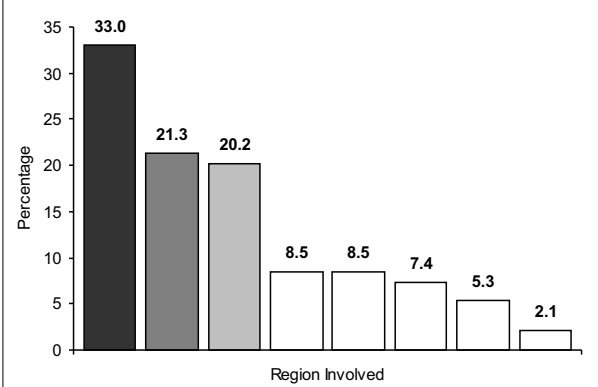

Q Leg/foot

$\square$ Thigh

$\square$ Perinium and genitalia

$\square$ Chest, Flank and Axilla

$\square$ gluteal and hip

$\square$ Arm/forearm/hand

口cevical

$\square$ Abdomen

Figure 2: Region involved

used antibiotics were tazocin (piperacilin + tazobactum) and clindamycin [Table 3].

Total $56.38 \%$ patients had type 1 necrotizing fasciitis and $43.4 \%$ of them multi- organ dysfunction syndrome (MODS) whereas $43.61 \%$ patients had type 2 necrotizing fasciitis and $51.2 \%$ of these cases had MODS. Type 1 infection was significantly higher in diabetic patients.

The overall mortality was $16 \%$, in type 1 necrotizing fasciitis the mortality was $15.1 \%$ while it was $17.1 \%$ in type 2 necrotizing fasciitis patients, the difference in mortality was not significant [Table 4].

\section{Discussion}

Necrotizing fasciitis is a surgical emergency, early diagnosis, prompt and aggressive debridment and definitive therapy in the intensive care environment had been demonstrated to improve outcome of this patients. ${ }^{[3,4]}$ However since meleney's time, the mortality associated with necrotizing fasciitis remained high, with a reported cumulative mortality of 34\% ranging from 6 to $76 \% .^{[5]}$ The difficulty in making early diagnosis is due to paucity of cutaneous finding in early course of the disease. ${ }^{[6]}$ These patients usually present with triad of

\section{Table 3: Antibiotics used and their frequency}

Tazocin (Piperacilin + tazobzctum) Count

Clindamycin

$69 \quad$ Frequency

Rocephine (Ceftrixion)

Metronidazole

Meropenam

Ciprofloxacin

Amikacine

Gentamycin

Vancomycin

60

11

11

11

11
11

11
13

13
4

3

73.4

63.8

11.7

22.3

11.7

11.7

13.8

4.3

3.2
Table 4: Type of necrotizing fasciitis and their association with diabetes mellitus and their outcome

\begin{tabular}{lccc}
\hline $\begin{array}{l}\text { Variable } \\
\text { MODS }\end{array}$ & Type I & Type II & Total \\
Yes & $23(43.4)$ & $21(51.2)$ & $44(46.8)$ \\
No & $30(56.6)$ & $20(48.8)$ & $50(53.2)$ \\
& $53(56.38)$ & $41(43.62)$ & $94(100)$ \\
NIDDM* $^{*}$ & & & \\
Yes & $38(71.7)$ & $15(36.5)$ & $53(56.4)$ \\
No & $15(28.3)$ & $26(63.4)$ & $41(43.6)$ \\
OUTCOME & & & \\
Survived & $45(84.9)$ & $34(82.9)$ & $79(84)$ \\
Died & $8(15.1)$ & $7(17.1)$ & $15(16)$ \\
\hline
\end{tabular}

${ }^{*} P$ value $<0.001$

There was no significant difference in the type of necrotizing faciitis according to MODS and in hospital deaths. Only NIDDM was significantly higher among the Type 1 cases and $P<0.001$, Figures in parentheses are in percentage 
symptoms exquisite pain, swelling and fever. If patients received NSAID, these medications will mask the manifestation with the disease still progressing, leading to delay in diagnosis and management. ${ }^{[7]}$ In this study, $48.9 \%$ patients had history of receiving NSAID.

Necrotizing fasciitis usually had some predisposing factor such as trauma, surgery, scratch or insect bite. ${ }^{[8]}$ In our patients, the most common predisposing factor was surgical procedure.

Most of the patients who are affected by necrotizing fasciitis have pre existing condition that renders them susceptible to infections. Conditions that results in immonocompramization in such patients includes advance age, chronic renal failure, peripheral vascular disease, drug abuse and diabetes mellitus. ${ }^{[9]}$ Diabetes mellitus was the common comorbid disease (56.4\%) in our patients. In diabetic patients high blood sugar levels is good media for bacterial growth and predisposes to an environment of low oxygen tension and rich in substance for bacterial growth. ${ }^{[10]}$

Necrotizing fasciitis can affect any region in the body, but most commonly effects extremities, perineum and truncal areas of the body. ${ }^{[1]}$ Patients with necrotizing fasciitis present with local signs of infection but severe pain disproportionate to local findings and associated with systemic toxic manifestations.$^{[12]}$ All our patients had leucocytosis and fever at admission to the hospital; leucocytosis is one of the indictor in laboratory risk indicators for necrotizing fasciitis (LRINEC) score for early diagnosis and differentiating necrotizing fasciitis from other soft tissue infections with more then $90 \%$ sensitivity and specificity. ${ }^{[13]}$ The new methods of diagnosis are computerized tomography (CT scan) magnetic resonance imaging (MRI) help make an early diagnosis of necrosis. MRI can detect the extent of necrotizing fasciitis and it can identify soft tissue edema infiltrating the facial plans, prior to local gangrenous cutaneous sign of infection, by many hours hence allowing rapid diagnosis and better outcome. ${ }^{[14]}$ But magnetic resonance imaging is not available in many situations and can delay the surgical procedure, secondly it can over- estimate the extent of deep facial involvement as the sensitivity of MRI exceeds its specificity. ${ }^{[15]}$ Other tests are needle biopsy or finger test, which can be performed at the bedside, in the ward. ${ }^{[16]}$ Patients included in our study were admitted to the surgical intensive care unit before or after debridment (mean SOFA score 8.6). The patients with necrotizing fasciitis had large volume of extra cellular fluid sequestrated in edematous wound or have capillary leakage, may have hemolysis and coagulation disorder. ${ }^{[17]}$ These patients may present to the hospital in a toxic shock state necessitating intensive care setup for proper management of these patients. During the first 24 hours of admission to SICU these patient received more then $4.8 \pm 2.2$ liters of fluid, $2.0 \pm 2.2$ units PRBC, $3.9 \pm 4.2$ unit FFP, $1.6 \pm 4.9$ units of platelet concentrate. Prompt and aggressive surgical debridment in corner stone of management of this soft tissue infection, number of debridment in our patients was $2.1 \pm 1.5$ times. After diagnostic delay, the most common pitfall was inadequate surgical debridment. The debridment should be aimed to remove all necrotic tissue, may be on a daily basis until the local infectious processes has been arrested. ${ }^{[18]}$

Necrotizing fasciitis has been divided into two types on the basis of microbiological culture. Type 1 necrotizing fasciitis is polymicrobial, usually caused by aerobic and anaerobic organism while Type 2 necrotizing fasciitis is caused by streptococci alone or with staphylococci. ${ }^{[19]}$ In our study $56.38 \%$ patients had type 1 infection and $43.62 \%$ had type 2 necrotizing fasciitis, $71.7 \%$ of diabetic patients had type1 necrotizing fasciitis, it learned from literature that type 1 necrotizing fasciitis was common in patients with diabetes mellitus. ${ }^{[20]}$ The toxic shock syndrome is commonly associated with type 2 necrotizing fasciitis and so is the multi organ dysfunction and mortality in these patients. ${ }^{[21]}$ In this study, $46.8 \%$ patients went into multi organ dysfunction and $51.2 \%$ of type 2 necrotizing fasciitis had MODS. Neutralization of circulating streptococcal toxins by administrating intravenous immunoglobulin is a desirable goal when hypotension present but definitive study and trail is needed to recommend its routine use, hyperbaric oxygen in treatment of this disease also needs clinical trail to justify it use. ${ }^{[22]}$ In our study, most of the patients received two antibiotics and the commonest were tazocin and clindamycin. When necrotizing fasciitis was treated with high doses of penicillin alone, it was less effective than expected, while the initial therapy with combination with protein synthesis inhibiting antibiotics especially clindamycin had a favorable outcome. ${ }^{[23]}$ Importance of use of clindamycin in treatment of necrotizing fasciitis 
as its use was associated with a reduction in mortality rate in necrotizing fasciitis; clindamycin is known to decrease the production of streptococcal toxins and enzymes even at sub inhibitory concentrations. ${ }^{[24]}$ When treating type1 necrotizing fasciitis aminoglycoside has to be added to the therapy. In this study our patients had a few unusual complication; $6.4 \%$ had ventricular tachycardia, 5.3\% had compartment syndrome causing acute renal failure and one patient of staphylococcal necrotizing fasciitis had tension penumothorax [Table 1]. ${ }^{[25]}$ Overall mortality in our patients was $16 \%$, which is lower, rang mentioned in literature.

\section{Conclusion}

Necrotizing fasciitis was more common in male and diabetic patients. Type 1 necrotizing fasciitis was common in our study and leg and foot was common region affected, overall mortality was lower, there was no significant difference in mortality in type 1 and type 2 necrotizing fasciitis patients.

\section{References}

1. Decamps V, Atiken J, Lee MG. Hippocrates on necrotizing fasciitis. Lancet 1994;344:556.

2. Wilson B. Necrotizing fasciitis. Am Surg 1952;18:416-31

3. Bilton BD, Zibari GB, McMillan RW, Aultman DF, Dunn G, McDonald JC. Aggressive surgical management of necrotizing fasciitis serve to decrease mortality: A retrospective study. Am Surg 1998;64:397-401.

4. Helmy AS, Salah MA, Nawara HA, Khatab H, Khalaf HA, Abd elMaguid N. Life threatening cervical necrotizing fasciitis. J R Coll Surg Edinb 1997;64:410-3.

5. Mchenny CR, Piotrowski JJ, Pertrinic D, Malagani MA. Determinants of mortality in necrotizing soft tissue infections. Ann Surg 1995;221:558-65.

6. Wong $\mathrm{CH}$, Chang HC, Pasupathy S, Khin LW, Tan JL, Low CO. Necrotizing fasciitis: Clinical presentation, microbiology and determinant of mortality. J Bone Joint Surg 2003;85:1454-60.

7. Veenstra RP, Manson WE, van der Werf TS, Fijen JW, Tulleken JE, Zijlstra JG, et al. Fulminant necrotizing fasciitis and nonsteriodal anti inflammatory drugs. Intensive Care Med $2001 ; 27: 1831$.

8. Singh G, Sinha SK, Adhikary S, Babu KS, Ray P, Khanna SK. Necrotizing infection of the soft tissue: A clinical profiles. Eur $\mathrm{J}$ Surg 2002;168:366-71.

9. Elliott DC, Kufera JA, Myers RA. Necrotizing soft tissue infections. Risk factors for mortality and strategies for management. Ann Surg 1996;224:672-83.

10. Wilkerson R, Paull W, Coville FV. Necrotizing fasciitis: A case report and review of literature. Clin Orth Rel Res 1987;216:187-92.

11. Hasham S, Matteucci P, Stanley PR, Hart NB. Necrotizing fasciitis. Br Med J 2005;330:830-3.

12. McHenry CR, Piotrowski JJ, Petrinic D, Malangoni MA. Determinant of mortality in necrotizing soft tissue infections. Ann Surg 1995;221:558-65.

13. Wong $\mathrm{CH}$, Khin LW, Heng KS, Tan KC, Low CO. The LRINEC (laboratory risk indicators for necrotizing fasciitis) score: A tool for distinguishing necrotizing fasciitis from other soft tissue infections. Crit Care Med 2004;32:1535-41.

14. Drake DB, Woods JA, Bill TJ, Kesser BW, Wenger MA, Neal JG, et al. Magnetic resonance imaging in early diagnosis of necrotizing fasciitis. J Emerg Med 1997;16:403-7.

15. Seal DV. Necrotizing fasciitis. Curr Opin Infect Dis 2001;14:127-32.

16. Andresen T, Green SD, Childers BJ. Massive soft tissue injury: Diagnosis and management of necrotizing fasciitis and purpura fulminans. Plast Reconstr Surg 2001;107:1025-35.

17. Lewis RT. Necrotizing soft tissue infections. Infect Dis Clin North Am 1992;6:693-700

18. Urschel JD. Necrotizing soft tissue infections. Postgrad Med J 1999;75:645-9.

19. Elliott D, Kufera JA, Myers RA. The microbiology of necrotizing soft tissue infections. Am J Surg 2000;179:61-6.

20. Brook I, Frazier EH. Clinical and microbiological features of necrotizing fasciitis. J Clin Microbial 1995;33:2582-7.

21. Kaul R, McGeer A, Low DE, Green K, Schwartz B. Populationbased surveillance for group $A$ streptococcal necrotizing fasciitis: Clinical features, prognostic indicators, and microbiologic analysis of seventy-seven cases. Ontario Group A Streptococcal Study. Am J Med 1997;103:18-24.

22. Yen JC, Feng Z. Salvage of limb and function in necrotizing fasciitis of the hand: Role of hyperbaric oxygen treatment and free muscle flap coverage. South Med J 2002;95:255-7.

23. Zimbelman J, Palmer A, Todd J. Improved outcome of clindamycin compared with beta-lactam antibiotic treatment for invasive Streptococcus pyogenes infection. Pediatr Infec Dis Jr 1999;18:1096-100.

24. Bakleh M, Wold LE, Mandrekar JN, Harmsen WS, Dimashkieh $\mathrm{HH}$, Baddour LM. Correlation of histopathological findings with clinical outcome in necrotizing Fasciitis. Clin Infect Dis 2005;40:410-4

25. Maheboob SN, Louon AM, Ahmed AH. Necrotizing fasciitis complicated by multiple pneumoceles. Saudi Med J 2003;24:12:1394-6.

26. Hscich WS, Yang PH, Chao HC. Necrotizing fasciitis: A case report of three cases and review of literature. Pediatrics 1999;103:53.

Source of Support: Nil, Conflict of Interest: None declared. 